\title{
Influence of Microbiological Fermented Feed Made from Pineapple Leaf Residues on Growth Performance and Meat Quality of Growing and Fattening Pigs
}

\author{
Du Jihua, Li Mingfu*, He Junyan, Zhang Jin, Lian Wenwei, Huang Tao \\ Institute of Agricultural Machinery, Chinese Academy of Tropical Agricultural Sciences \\ (CATAS),Zhanjiang 524091, Guangdong, P.R. China \\ dujihua050609@163.com; Limingfu378@163.com
}

\begin{abstract}
Key words: pineapple leaf residues; growing and fattening pigs; growth performance; meat quality Abstract.Waste pineapple leaf residues were used to make microbiological fermented feed. 60 pigs with the same age in days and the weight of about $40 \mathrm{~kg}$, and they were divided into 4 groups (A, B, $\mathrm{C}$ and D) at random. Group A served as the control group. The addition amount of pineapple leaf residues in the experimental groups $(\mathrm{B}, \mathrm{C}$ and $\mathrm{D})$ was calculated with dry matters, and pineapple leaf residues were used to replace $4 \%, 8 \%$ and $12 \%$ of concentrated feed respectively. After $90 \mathrm{~d}$ feeding experiment, the growth performance, blood index and meat quality of the pigs were analyzed and evaluated. The results show that (1)the average daily weight gain of growing and fattening pigs in the control group $\mathrm{A}$ and experimental groups $\mathrm{B}, \mathrm{C}$ and $\mathrm{D}$ is $0.85,0.9,0.81$ and $0.79 \mathrm{~kg}$ respectively. (2)Blood biochemical indexes of control group and experimental groups have no significant difference. (3) Through comparison of meat quality and nutrition, the meat quality of pigs in experimental groups is superior to that of pigs in control group.
\end{abstract}

\section{Introduction}

Annual output of pineapple leaves is about 10 million tons in the tropical zone of south China. At present, pineapple leaves are mainly used for fiber extraction and fertilizer. The leaves in some areas are discarded or burnt. During fiber extraction, large quantities of leaf residues will be generated. If leaf residues can be utilized effectively, environmental pollution can be reduced, and resource supply and demand contradiction can be relieved. Hence, it is an important way to achieve sustainable development. Researches show that pineapple leaves are rich in nutritional ingredients and can serve as superior greenfeed source. If these pineapple leaves are scientifically treated to change waste material into things of value, this will contribute to achieve sustainable development of southern planting industry and breeding industry.

With global popularization of speeded-up pigs and excessive use of chemical agents and antibiotics in the feed, the taste of pork is poor, and the savoury and mellow taste is totally lost. The reduction of taste and quality of pork becomes a common problem nationwide.

In this paper, the influence of addition of pineapple leaf residues in the feed to replace some concentrated feed on pig raising cost and meat quality is studied, and the influence is evaluated. This can not just solve resource waste and environmental pollution caused by the abandonment of pineapple leaf residues, but also improve feeding mode of growing and fattening pigs, improve meat quality and taste and offer support for livestock husbandry development in the tropical zone.

\section{Experiment design and method}

Preparation of microbiological fermented feed. The waste pineapple leaf residues were collected after pineapple leaf fiber was extracted. Then, EM bacteria liquid was sprayed evenly, and 
pineapple leaf residues were stored in the food-grade plastic drums for compaction and sealing. The fermentation was finished after 30 days. If the fermented pineapple leaf residues have acid smell, and the color is yellow green, with the PH between 3.8 and 4.4, they are superior fermented feed and can be used for the experiment.

Experiment site and pigs for the experiment. The experiment site is located at Gaoyang Pig Farm in Mazhang District, Zhanjiang City, Guangdong Province. Duroc-Yorshire-Landrace pigs were chosen as the objects of experiment.

Experiment design. 60 growing and fattening pigs with the same age in days and the weight of about $40 \mathrm{~kg}$, and they were divided into 4 groups (A, B, C and D) at random. There were two repetitions in each group, and 15 pigs were included in each repetition. Group A served as the control group. The addition amount of pineapple leaf residues in the experimental groups $(\mathrm{B}, \mathrm{C}$ and D) was calculated with dry matters, and pineapple leaf residues were used to replace $4 \%, 8 \%$ and $12 \%$ of concentrated feed respectively. The pre-feeing period was $15 \mathrm{~d}$. In the beginning, the pigs were fed with a small amount of pineapple leaf residues. After the experimental groups adapted, the formal experiment period ( $90 \mathrm{~d}$ in total) started. The microbiological fermented feed made from pineapple leaf residues and concentrated feed were mixed to feed the experimental groups, while only concentrated feed was used to feed the control group. The experiment was implemented in the same pig house, and environmental conditions such as ventilation and light were consistent. In the experiment period, the management was subject to routine management requirements of the pig farm, and feed intake, defecation, urination, dynamics, health and behaviors of pigs were observed.

\section{Index measurement.}

The pigs were made empty stomach for $12 \mathrm{~h} 1 \mathrm{~d}$ before they became fully grown and ready for slaughter. Each individual pig was weighted, and food intake and weight gain of each group were figured out. Besides, the feeding effect was evaluated. The experimental group and control group with the optimal addition ratio were chosen for contrastive analysis of blood biochemical indexes and meat quality.

Production performance indexes were measured, including initial weight on an empty stomach, final weigh on an empty stomach, total consumption of feed, total consumption of leaf residues, weight gain and average daily weight gain. Blood biochemical indexes were measured, including alanine aminotransferase (U/l), total protein $(\mathrm{g} / \mathrm{l})$, albumin $(\mathrm{g} / \mathrm{l})$, globulin $(\mathrm{g} / \mathrm{l})$, total cholesterol $(\mathrm{mmol} / \mathrm{l})$ and urea nitrogen $(\mathrm{mmol} / \mathrm{l})$ etc. Meat quality was measured, including meat color, rate of water loss, drip loss, cooked meat percentage, intramscular fat content and the content of 16 hydrolyzed amino acids etc.

Data processing. All original data were preliminarily processed with MICROSOFT EXCEL software, and then SPSS19.0 statistical software was used for systematic analysis.

\section{Result analysis}

Influence of addition of pineapple leaf residues in daily feed on growth performance of growing and fattening pigs. The average daily weight gain of control group A and experimental groups $\mathrm{B}, \mathrm{C}$ and $\mathrm{D}$ was $0.85,0.9,0.81$ and $0.79 \mathrm{~kg}$ respectively (Fig. 1 ). The results show that the addition of $4 \%, 8 \%$ and $12 \%$ of pineapple leaf residue silage in the daily feed during the growing and fattening period has no significant influence on the weight gain, but the addition of $4 \%$ of pineapple leaf residue silage presents the optimal effect. Pineapple leaf residues in Group C (8\%) and Group D (12\%) fail to promote weight gain of growing and fattening pigs, and the weight gain is slightly lower than that in the control group. Pineapple leaf residue feed contains a large amount of coarse fibers. Although coarse fiber has a positive effect on the health of pigs, it is hard to digest, 
and pigs will consume much energy in the digestion and absorption process. This is also the reason for low weight gain in the two groups. The addition of $4 \%$ of pineapple leaf residue silage for Group B is beneficial to healthy growth of pigs, without the influence of weight gain.

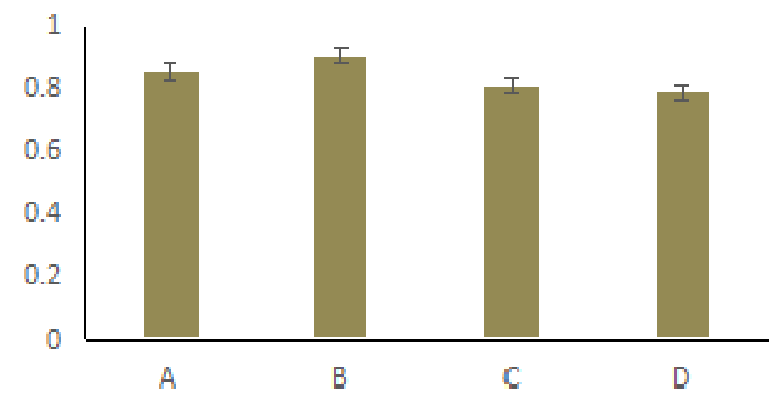

Fig.1 Average daily weight gain per pig $(\mathrm{kg})$

Influence of addition of pineapple leaf residues in daily feed on health of growing and fattening pigs. Since the experimental group B shows a good feeding effect, Group B was chosen to compare with Group A in terms of blood biochemical indexes and meat quality.

Blood participates in body metabolism and every functional activity, so blood plays an important role in guaranteeing body metabolism and functional adjustment and balancing internal and external environment of body. The results of blood routine examination show that various indexes in the experimental group and the control group have no significant difference (Table 1). This indicates that the addition of pineapple leaf residues has no adverse effect on the healthy growth of growing and fattening pigs. In addition, it is found that feeding activity of pigs in the experimental group is frequent, and the pigs grab food obviously, with bright and clean hair color and healthy signs. As well, the growth performance is superior to the control group.

It is also found that individual pigs particular about food show non-active food intake, small food consumption, slow growth rate and thin body under the condition of concentrated feed feeding. But after the addition of pineapple leaf residues, the pigs show frequent food grabbing phenomenon, the increase in the food consumption, obvious weight gain and good health. This indicates pineapple leaf residues can promote food intake ad help digest and they are beneficial to healthy growth of pigs.

Table 1 Influence of pineapple leaf residue feeding on blood biochemical indexes

\begin{tabular}{lll}
\hline \multicolumn{1}{c}{ Examination item } & $\begin{array}{c}\text { Control } \\
\text { group }\end{array}$ & $\begin{array}{c}\text { Experimental } \\
\text { group }\end{array}$ \\
\hline $\begin{array}{l}\text { Alanine aminotransferase } \\
(\mathrm{U} / 1)\end{array}$ & $41.2 \pm 2.12$ & $52.03 \pm 1.77$ \\
Total protein $(\mathrm{g} / \mathrm{l})$ & $61.4 \pm 1.91$ & $56.97 \pm 2.83$ \\
Albumin $(\mathrm{g} / \mathrm{l})$ & $31.95 \pm 0.49$ & $34.8 \pm 0.57$ \\
Globulin $(\mathrm{g} / \mathrm{l})$ & $29.45 \pm 1.48$ & $22.17 \pm 1.63$ \\
Glucose $(\mathrm{mol} / \mathrm{L})$ & $4.45 \pm 1.62$ & $3.80 \pm 0.96$ \\
Urea nitrogen $(\mathrm{mmol} / \mathrm{l})$ & $4.91 \pm 0.42$ & $5.01 \pm 0.35$ \\
Total cholesterol $(\mathrm{mmol} / 1)$ & $1.9 \pm 0.45$ & $2.28 \pm 0.57$ \\
Triglyceride $(\mathrm{mmol} / \mathrm{l})$ & $0.39 \pm 0.78$ & $0.32 \pm 0.94$ \\
\hline
\end{tabular}

Influence of addition of pineapple leaf residues in daily feed on meat quality of growing and fattening pigs. $\mathrm{PH}$ in both control group and experimental group accords with the standard of 
high-quality pork. Within $24 \mathrm{~h}$ after slaughter, $\mathrm{pH}$ decline of experimental group is slower. Thus, the fresh degree of pork can extend, and the occurrence of PSE pork can decrease (Table 2). The rate of water loss in the experimental group is significantly lower than that in the control group $(\mathrm{P}<0.05)$. This indicates that with the rise in fat content in muscle, tenderness also improves. Besides, intramscular fat content improves; pork tenderness increases; taste decline problem of lean pigs improves. Hence, pineapple leaf residues play a positive role in improving meat quality and taste.

Through comparison of meat quality and nutrition, the meat quality of experimental group is better than that of control group. So, the addition of pineapple leaf residues can facilitate healthy growth of growing and fattening pigs and enhance carcass and meat quality. Therefore, pineapple leaf residues deserve to be popularized and applied in production.

Table 2 Influence of addition of pineapple leaf residues on meat quality

\begin{tabular}{lll}
\hline & Control group & Experimental group \\
\hline Flesh color & $2.83 \pm 0.29$ & $3.17 \pm 0.29$ \\
Rate of water loss \% & $9.11 \pm 1.85$ & $4.89 \pm 1.04$ \\
$\mathrm{pH} 24$ & $5.62 \pm 0.03$ & $5.81 \pm 0.17$ \\
Cooked meat percentage \% & $61.3 \pm 2.45$ & $60.77 \pm 1.05$ \\
\hline
\end{tabular}

Table 3 Influence of addition of pineapple leaf residues on nutrition of pork

\begin{tabular}{lll}
\hline Analysis item & $\begin{array}{l}\text { Mean value of control group } \\
(\mathrm{g} / 100 \mathrm{~g})\end{array}$ & $\begin{array}{c}\text { Mean value of experimental } \\
\text { group }(\mathrm{g} / 100 \mathrm{~g})\end{array}$ \\
\hline ASP & 2.08 & 2.02 \\
THR & 1 & 0.98 \\
SER & 0.87 & 0.89 \\
GLU & 3.59 & 3.41 \\
GLY & 0.9 & 0.87 \\
ALA & 1.51 & 1.53 \\
VAL & 1.18 & 1.12 \\
MET & 0.66 & 0.63 \\
ILE & 1.09 & 1.01 \\
LEU & 1.87 & 1.81 \\
TYR & 0.79 & 0.78 \\
PHE & 1.1 & 1.09 \\
HIS & 0.85 & 0.86 \\
LTS & 2.11 & 2.04 \\
ARG & 1.62 & 1.56 \\
PRO & 0.86 & 0.86 \\
Total of 16 hydrolyzed & 22.1 & 21.5 \\
amino acids & 22.5 & 22.1 \\
Protein & 3.1 & 3.2 \\
Intramuscular fat & &
\end{tabular}




\section{Conclusion}

At present, selection and breeding of lean pigs are strongly popularized in China, but the selection of lean meat percentage has made the intramscular fat content drop to $1 \%-1.5 \%$, lower than the standard range (2.5\%-3.\%). Thus, the taste of pork greatly decreases. Based on the research results in this paper, pineapple leaf residue is a kind of greenfeed source with rich nutrients. Replacing concentrated feed with $4 \%$ of pineapple leaf residues can improve growth performance of growing and fattening pigs. Moreover, pineapple leaf residues can facilitate food intake and digestion of growing and fattening pigs, improve pork quality and taste. Pineapple leaf residues as the feed of pigs are safe and feasible. Therefore, pineapple leaf residues deserve to be popularized and applied in production.

\section{Acknowledgements}

This project is supported by the special project of basic scientific research expense of Chinese Academy of Tropical Agricultural Sciences (1630132016020).

\section{References}

[1] Gong Pu, Zhang Jing, Lian Wenwei et al. Research Status and Analysis on Utilization of Main Tropical Crop Wastes as Feed [J]. Guangdong Agricultural Sciences, Vol.17,(2012), p.118-120.

[2] Li Mingfu, Zhang Jing, Lian Wenwwei et al. Pineapple Leaf Residue Silage Technology [J]. China Herbivores, Vol.25-6, (2005)p.58-59.

[3] Li Na, Wang Wei, Jin Xin et al. Influence of Addition of Alfalfa Meal in Daily Feed on Growth Performance and Meat Quality of Songliao Black Pigs [J]. Pig Feeding, (2010), p.37-40.

[4] Yi Xianfeng, Deng Suyuan, Cao Shuwei. Study on Influence of Alfalfa on Growth Performance and Blood Biochemical Indexes of Mutton [J]. Ruminant Nutrition, (2015), p.435-437.

[5] Li Mingfu, He Junyan, Lian Wenwei et al. Research Status and Development of Pineapple Leaf Feed Utilization [J]. Tropical Agricultural Engineering, Vol.35-4, (2011), p.9-11.

[6] Zhang Haisheng. Analysis on Processing Utilization Technology and Research Status of China's Pineapple Resources [J]. Academic Periodical of Farm Products Processing, Vol.12, (2012) p.111-123.

[7] Lian Wenwei, Zhang Jing, Li Mingfu et al. Exploration on Use of Pineapple Leaf Silage in Pig Feeding [J]. Guangxi Tropical Agriculture, Vol.4(2002), p.6-7. 